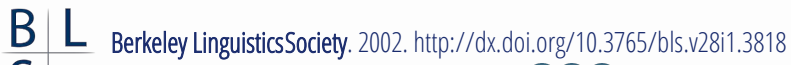

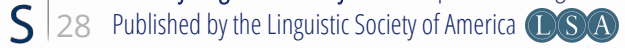

\section{Unpacking the Okanagan Person-Marking Conundrum}

\author{
PAUL BARTHMAIER \\ University of California, Santa Barbara
}

\section{Introduction}

Okanagan, a Southern Interior Salish language spoken in northern Washington state and southern British Columbia, exhibits a peculiar set of pronominal morphemes that surely are a testament to a diverse and varied history. From the outside, the pronominal markers associated with Okanagan clauses appear to be a disparate group of morphemes. A lack of formal similarity frustrates attempts to characterize them as either nominative-accusative or ergative-absolutive. Morphologically the pronominal forms appear to be the typologically rare tripartite system. Yet, speakers have little trouble using the different markers in their appropriate contexts. In what follows, I will propose an analysis of how the person marking in the language has come to have such an interesting shape. I will offer internal and external motivations that the system responded to as it evolved into its current form.

Okanagan has been investigated by several different researchers, the most notable of whom, Anthony Mattina, has continuously studied the language since the late 1960s. In his recent paper (A. Mattina 2001), he describes four pronominal sets, summarized in the tables below. If four sets of pronominal marking were not complicated enough, a language learner must also contend with homophonous forms overlapping paradigms and a host of allomorphy some of which has no reasonable explanation in the phonology. (Parenthesized elements in the above tables are subject to regular phonological processes in the language such as deletion in unstressed environments and coronal simplification.)

\begin{tabular}{|c|c|c|}
\hline & \multicolumn{2}{|c|}{ Intransitive } \\
\hline & $\mathrm{sg}$ & P1 \\
\hline 1 & $\mathrm{kn}=$ & $\mathrm{k}^{\mathrm{w}} \mathrm{u}=$ \\
\hline 2 & $\mathrm{k}^{\mathrm{w}}=$ & $p=$ \\
\hline 3 & $\varnothing$ & $\varnothing \ldots-1 x$ \\
\hline
\end{tabular}

\begin{tabular}{|c|c|c|}
\hline & \multicolumn{2}{|c|}{ Genitive Subject $^{1}$} \\
\hline & $\mathrm{sg}$ & $\mathrm{pl}$ \\
\hline 1 & i(n)- & $-\mathrm{tt}$ \\
\hline 2 & $a(n)-$ & $-m p$ \\
\hline 3 & $-\mathrm{s} /-\mathrm{c}$ & $-s-1 x /-c-1 x$ \\
\hline
\end{tabular}

'A. Mattina (2001) labels this paradigm 'possessive,' but elsewhere he has used 'genitive'. For further discussion of this category label see A. Mattina (1993) and N. Mattina (1996). 


\begin{tabular}{|c|c|c|}
\hline & \multicolumn{2}{|c|}{ Transitive Subject } \\
\hline & sg & $\mathrm{Pl}$ \\
\hline 1 & $-(i) n$ & $-(\mathrm{i}) \mathrm{m} / \mathrm{-t}$ \\
\hline 2 & $-(i) \mathrm{x}^{\mathrm{w}}$ & $-(i) p$ \\
\hline 3 & $-(i) s$ & -(i)s-lx \\
\hline
\end{tabular}

\begin{tabular}{|c|c|c|}
\cline { 2 - 3 } \multicolumn{1}{c|}{} & \multicolumn{2}{c|}{ Transitive Object } \\
\cline { 2 - 3 } \multicolumn{1}{c|}{} & $\mathrm{sg}$ & $\mathrm{pl}$ \\
\hline 1 & $\mathrm{k}^{\mathrm{w}} \mathbf{u}=$ & $\mathrm{k}^{\mathbf{w}} \mathbf{u}=\ldots-\mathrm{m}$ \\
\hline 2 & $-\mathrm{s} /-\mathrm{m}$ & $-\downarrow(\mathbf{u} \mathrm{l}) \mathrm{m}$ \\
\hline 3 & $-\varnothing$ & $-\varnothing \ldots-\mathrm{l} \mathbf{x}$ \\
\hline
\end{tabular}

Finding the same consonants, particularly $-m,-s$, and $-t$, recurring across so many forms is somewhat surprising in a language like Okanagan, which has almost forty consonants in its inventory. But, if we focus on individual sections of the grammar one at a time, we can explain why we see the same consonants in so many forms. Borrowing may account for some of the changes, but the modern system is also the result of detransitivization, grammaticization, and reanalysis. This process has led to a radical restructuring of a crucial portion of core grammar which we still see today.

\section{Possessive marking}

The first step towards simplifying the person-marking puzzle is to point out that one set of markers, the 'Genitive Subject', is identical in form to the possessive markers in the language. Although genitive subjects and possessive morphemes are employed in distinct sections of the grammar, their formal similarity warrants a unifying diachronic explanation. The examples in (1) have morphemes circled which correspond to underlined pronouns in the glosses.

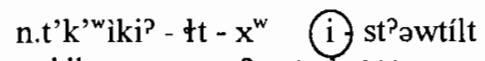

saddle.up - DITR -2ERG IPOSS-youngest.boy ${ }^{3}$

You will saddle it up for my youngest boy

way' x̌às - $t$ sq'líps

DM be.good-STA 2POSS-handkerchief

Your handkerchief is pretty

$$
\begin{array}{lllll}
\text { way' } & \text { kan - xit - am } & \text { i? } & t & \text { 1.'Piw - } \\
\text { DM } & \text { help - BEN - INTR } & \text { DET } & \text { OBL } & \text { father-3POSS }
\end{array}
$$

His father helped him

The above Okanagan examples show typical predicate-initial clauses with single arguments. The predicate describes an event or state and is marked with verbal

\footnotetext{
${ }^{2}$ The majority of examples come from Mattina (1985) The Golden Woman, an Okanagan narrative tale told by Peter J. Seymour to Anthony Mattina. Examples numbers correspond to the line number of the published text.

3 Abbreviations used are: $\mathrm{ASP}=$ aspect, $\mathrm{BEN}=$ benefactive transitivizer, $\mathrm{DET}=$ determiner, $\mathrm{DIR}=$ directional, $\mathrm{DITR}=$ ditransitive, $\mathrm{DM}=$ discourse marker, $\mathrm{DST}=$ distributive, $E \mathrm{EG}=$ ergative, EVID=evidential, INTR=intransitive, IMP=imperative, IRR=irrealis, LOC=locative, HTR=high transitivity, LTR=low transitivity, MUT=mutative, $\mathrm{NC}=$ non-control, $\mathrm{NEG}=$ negative, $\mathrm{NOM}=$ nominalizer, $\mathrm{OBL}=$ oblique, $\mathrm{POSS}=$ possessive, $\mathrm{RCP}=$ reciprocal, $\mathrm{RDP}=$ reduplication, RES $=$ resultative, $S T A=$ stative.
} 
morphology. In each example the argument is a nominal which is affixed by a possessive marker. In the following, we will see that the construction types found in (1) serve as a model for many other constructions.

Cross-linguistically, nominalizations have been recognized as a common strategy for identifying complements. In English, nominalizations are used as one type of complementation strategy. Consider the following examples.

(2a) The Taliban destroyed the Buddha statue.

(2b) [The Taliban's destruction of the Buddha statue] angered many people.

The clause in (2a) is nominalized in order to be used as the subject argument of (2b). Note that word order is preserved, the subject and verb of (2a) are in a genitive relationship and the object is an oblique.

Nominalization also appears to be an important grammatical resource of Okanagan as a way of identifying arguments.

$\mathrm{c}-\mathrm{my}-\mathrm{st}$ - is $\quad \mathrm{i}$ S $\mathrm{k}^{\mathrm{w} u} \mathrm{u}-\mathrm{st}-\mathrm{am}$

ASP-know - LTR -3ERG 1POSS-NOM-send-LTR-INTR

He'll know that I sent you (lit. He'll know it was my sending)

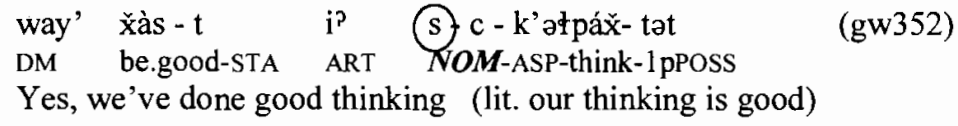

The intransitive clauses in (3) show a pattern similar to those in (2); each clause consists of a predicate with verbal morphology and a single argument, yet the arguments in (3) have a semantic core which is verbal. In order for an event to be an argument, the grammar requires that the clause be nominalized. In the above examples, the nominalizer is circled and the boldface in the gloss line shows its use as a nominalizer. This strategy is common in Salish and appears to go back to Proto-Salish (Kroeber 1999). In these nominalizations, the possessive morphology corresponds to the subjects of the nominalized clauses.

The examples in (3) only partially describe the picture because the arguments are grammatically intransitive. Transitive subjects of nominalizations look virtually the same as intransitive subjects, but objects are curiously marked by a proclitic from the intransitive subject set. N. Mattina (1996) labels the intransitive set the 'absolutive paradigm', presumably because these forms mark subjects of intransitive clauses and objects of nominalized clauses.
ut my - p- nú - s t incà?
DM know-MUT-NC-3ERG OBL I
$\mathrm{k}^{\mathrm{w}}=-\mathrm{s}-\mathrm{s}-\mathrm{k}^{\mathrm{w}} \mathrm{u} \mathrm{l}-\mathrm{st}-2 \mathrm{~m} \quad(\mathrm{gw} 127)$
2 lPOSS-NOM-send-LTR-INTR
He'll know that I sent you

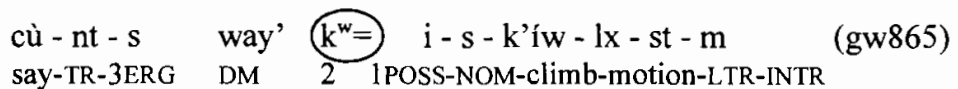$$
\text { She'll say to you, 'I'll take you upstairs...' }
$$ 
In both examples above, the subject of the nominalized clause is marked by the possessive morpheme $i(n-)$ and the object by the intransitive subject morpheme $k^{w}=$. Example (4a) also nicely illustrates the argument structure of the transitive predicate mypnús 'He'll know X' in that X must be interpreted as the nominalized clause. The emphatic pronoun, incà? ' $\mathrm{I}$ ', is necessarily marked as oblique. Thus the two core arguments are the nominalized clause and the third person subject which is marked on the predicate by the ergative $-s$.

Nominalization is also employed in some Okanagan negation strategies. Payne (1997) explains that languages may have several different strategies for negation and one common type is nominalization.

$$
\begin{aligned}
& \text { lut } \quad t^{\prime}=\quad i-k-s-\text { on }-x^{w} s t-i^{w} k^{w} \\
& \text { NEG EVID 1POSS-IRR-NOM-LOC-walk-water } \\
& \text { I'm not going to wade in the water. }
\end{aligned}
$$

$$
\begin{array}{lll}
\text { lut } & \mathrm{k}^{\mathrm{w}}=\quad \mathrm{t}^{\prime}=\quad \mathrm{i}-\mathrm{k}-\mathrm{s}-\mathrm{x}^{\mathrm{w}} \text { íc' }- \text { əłt }- \text { əm } \\
\text { NEG } & 2 \quad \text { EVID 1POSS-IRR-NOM-give-DITR-INTR } \\
\text { I'm not going to hand it to you, }
\end{array}
$$

The negative, lut, has a single nominalized argument where the subject of the nominalized clause is marked by the possessive set and the object by the intransitive set.

During the diachronic progression of the grammar, the nominalization schema seems to have been further extended in Okanagan as a means of signaling interclausal dependencies. Kroeber (1996) proposes for Thompson Salish that nominalization of this type may be thought of as a clause-chaining device where the nominalizer is seen as marking a predicate as non-finite. The example in (5), which is taken from A. Mattina (1985), suggests that this may be a useful notion for Okanagan as well. It consists of a sequence of three clauses. In the third clause, Mattina's gloss certainly indicates that the clause is pragmatically and perhaps syntactically dependent, yet the clause has no overt marker of dependency other than the nominalization.

$$
\begin{aligned}
& \text { yəy'à - } t \text { stìm' x̌mìnk - ant - } p \\
& \text { all - STA what want - HTR - 2pERG }
\end{aligned}
$$




\section{Unpacking the Okanagan Person-Marking Conundrum}

This example represents a different use of possessive morphology than was seen in (4). Here the nominalized clause is not an argument of any verb; rather it provides adverbial information to the discourse. The use of free-standing nonfinite constructions to add circumstantial or adverbial information to a discourse is a common strategy seen in clause-chaining languages.

The final step in the process of evolution of nominalization seems to be the use of nominalized clauses as seemingly independent clauses.

$$
\begin{aligned}
& \text { cù-s lut at'ip } \mathrm{k}^{\mathrm{w}}=\mathrm{t}=\mathrm{i}-\mathrm{k}-\mathrm{s}-\mathrm{twn}-\mathrm{i}^{\prime} \mathrm{kst}-\text {-m }(\mathrm{gw} 362) \\
& \text { say-3ERG NEG because } 2 \text { EVID 1POSS-NOM-leave-hand-INTR } \\
& \text { He said: "No, I'm (not) going to let you go, } \\
& \text { way' } \mathrm{k}^{\mathrm{w}}=\mathrm{i}-\mathrm{s}-\mathrm{c}-\lambda^{\prime} \mathrm{P}^{\mathrm{a}}-\mathrm{m} \\
& \text { DM } 2 \text { 1POSS-NOM-ASP-look.for-INTR }
\end{aligned}
$$

The gloss in (7) does not indicate a dependency relationship like the one in (7), although a dependent interpretation might not be infelicitous. The second clause provides the reason for doing the first. The many examples like the one in (7) help explain the motivation for the synchronic category label 'genitive subject', but a diachronic approach sheds greater light on the complexity of the history and its use in discourse.

To summarize, what began as a simple kernel in the morphology of the language has apparently been exploited by speakers of Okanagan for several different grammatical purposes. That is, nominalization and possessive marking has spread from the level of morphology to the syntax and pragmatics of the language as a grammatical device which provides a means of accomplishing several different functions. Synchronically we find the possessive morphemes operating with nominalized clauses to indicate not only possession, but also arguments of predicates, interclausal dependencies, and even seemingly independent clauses.

\section{Second Person Singular Object}

The second piece of the puzzle involves the second person singular object forms. They are represented by two, phonologically unrelated allomorphs: $-s$ and $-m$. The choice between the two allomorphs is sensitive to the transitivizer of the predicate. It can easily be shown that $-s$ is found with the higher-transitivity predicates and $-m$ with the lower-transitivity predicates. Newman (1979b), in his reconstruction of Salish object forms, proposes two paradigms which he calls the 'neutral object' and the 'causative object.' For second persons, the neutral object forms in the Salishan family usually have an $-s$ and the causative objects usually have an $-m$, except where the forms have been 'replaced.'

Newman's analysis is complementary to the one presented here in that neutral object paradigms pair with higher transitive predicates and causative objects correspond to lower transitivity predicates. However, his reconstruction suggests that this patterning could go back to Proto-Salish, a claim which may be debatable 
and one that would obfuscate any internal motivation which may exist. In what follows, I present an analysis of the internal restructuring of the Okanagan pronominal system, and I elaborate on the functional motivations behind this reorganization. This analysis will not dispute the shape of the pronominal forms, but it may begin to answer questions like how or why they have come to have their shape.

To begin, it may be helpful to note that the order of morphemes in the Okanagan transitive predicate is:

\begin{tabular}{|l|l|l|l|l|}
\hline (aspect) & stem & transitivizer & object & subject \\
\hline
\end{tabular}

Mattina and Montler (1990) present the following data illustrating the sensitivity of the second person object morpheme to the transitivizer.

$\begin{array}{lll}\text { subject } & \text { strong root } & \text { weak root } \\ \text { I } & \text { wík-nt-(S-n } & \text { c'lx-nt-(S)-in }^{\prime} \\ \text { he } & \text { I saw you } & \text { I grabbed you } \\ & \text { wík-nt-s } & \text { c'lx-nt-(S)-ís } \\ & \text { he saw you } & \text { he grabbed you }\end{array}$

\section{-st transitivizer}

$$
\text { strong root }
$$

wík-st (m-n

I usually see you

wík-st (m)-s

he usually sees you weak root

c'lx-st úm-n

I usually grab you

c'lx-st úm -s

he usually grabs you

In the above examples, the morpheme in question is circled and its gloss is in boldface. Before proceeding with the discussion of the pronominal forms, a few points about the data are worthy of attention. Firstly, the forms given under $-s t$ transitivizer are presented for illustrative purposes, but are unattested without the aspect marker ac-/c- ${ }^{4}$ (N. Mattina 1996:72) Secondly, the two transitivizers discussed here have reflexes in all of the Salish languages and have received various labels. Following Hopper and Thompson (1980), I refer to clauses with $n t$ as higher transitivity because of their association with telic volitional actions and $-s t$ clauses as lower transitivity because of their non-punctual interpretation. ${ }^{5}$

The examples in (9) clearly show that there are two distinct morphemes referring to second person objects. Perhaps more interestingly, it seems that the current alternation is the result of two different paths, neither of which originated with second person morphemes. Although from two different diachronic sources, the stimulus for development was the same: a politeness ploy to defocus second person.

The likely source of the $-s$ is the third person marker. The use of third person pronominals for second person is well known in many languages including

\footnotetext{
${ }^{4}$ For a full description of Okanagan aspect, see N. Mattina (1996).

${ }^{5}$ Transitivity in Okanagan has received a good deal of attention. See A. Mattina (1978a/b), A. Mattina (1982), and Hebert (1982b). For a broader description of the family, see Thompson (1985).
} 


\section{Unpacking the Okanagan Person-Marking Conundrum}

German, French, Spanish and Hungarian. This type of replacement tends to happen for formal second person forms. Over the diachronic development of Okanagan grammar, in formal situations, speakers may have used third person markers as a means of deflecting from the more salient speech act participants' role to the third person. Eventually the formal forms replaced the familiar terms and they became the only means of reference. This process is analogous to the situation in German where the pronoun sie 'they' has come to be used for formal second persons. On this continent, Frachtenberg (1922) describes a similar pattern in Siuslaw where third person plural is also used for second person singular.

The source of the second alternant $-m$ is actually the pan-Salishan marker of intransitivity. Detransitivization served as a means of defocusing the agent. In Okanagan this change occurred in lower-transitivity clauses with second person agents. That is, the clauses which were semantically lower transitivity, a la Hopper and Thompson (1980), were marked as grammatically intransitive with the morpheme $-m$. Historically, this may be due in part because the $-s t$ transitivizer implicated an agent that was low in potency. However, synchronically the only evidence of detransitivization is the morpheme $-m$. Presumably the resulting intransitive clause could have had an optional oblique second person. Eventually these intransitive constructions were reanalyzed as transitive (when the detransitivizing $-m$ was interpreted as referring to a second person patient) and the clauses marked with the transitive subject suffixes.

\section{First Person Plural Transitive Subject}

The third piece of the puzzle also involves detransitivization, but in this case it began as a strategy for what A. Mattina (1973) calls 'third-person indefinite forms'. Interestingly, Newman (1979a) does not discuss the allomorphy of first person plural transitive subject markers $-t /-m$. Based on comparative evidence we know the $-t$ represents the older form, but where the $-m$ came from may not be immediately obvious. Again, there is good motivation for the detransitivizing $-m$ to play a role.

A. Mattina (1973) observed the homophony of third-person indefinite forms and transitive clauses with first person agents and third person patients. The diachronic path linking the two may look something like the following. As a first pass the detransitivized construction resembled a passive, as in 'The cake was eaten.' This form was used to highlight the patient and defocus the agent. In time this was interpreted as a third person indefinite form, as in 'Somebody ate the cake.' Eventually this third person indefinite construction was reanalyzed as a first person plural form in a scheme that is analogous to the facts surrounding the French on, as in on arrive = 'We're here!' But the plan was not adopted wholesale and today we are left with the present allomorphy of $-(i) m /-t$. 
(10)

\begin{tabular}{|c|c|c|c|c|}
\hline \multirow{3}{*}{ You } & strong root & weak root & strong root & weak root \\
\hline & wík-nt-s - t & $c^{\prime} l x-n t-s$ if & wík-st-m $\oplus$ & c'lx-st-úm (t) \\
\hline & We saw you & We grabbed you & $\frac{\text { We usually see }}{\text { you }}$ & $\frac{\text { We usualiy grab }}{\text { you }}$ \\
\hline \multirow[t]{2}{*}{$3^{\text {rd }}$ person } & wík-nt (m) & $c^{\prime} 1 x-n t-1 \mathrm{~m}$ & wík-st -m & c'lx-st - im \\
\hline & We saw him & We grabbed him & $\frac{\text { We usually see }}{\text { him }}$ & $\frac{\text { We usually grab }}{\text { him }}$ \\
\hline \multirow[t]{2}{*}{ indefinite } & wík-nt -m & c'lx-nt-(im) & wík-st -m & $c^{\prime} l x-s t-$ im \\
\hline & $\frac{\text { Somebody }}{\text { saw you }}$ & $\frac{\text { Somebody }}{\text { grabbed you }}$ & $\frac{\text { Somebody }}{\text { usually sees you }}$ & $\frac{\text { Somebody }}{\text { usually gra }}$ \\
\hline
\end{tabular}

Immediately we notice the homophony of the Okanagan forms involving third person objects and indefinites, shown above on the second and third lines. The first person plural $-m$ crept into the grammar along the aforementioned path, but, as seen on the first line of Okanagan forms, the morpheme remained $t$ with second person objects. The first person plural allomorph $-m$ is reserved for use only in constructions which also involve third person objects.

\section{First Person $\mathbf{k}^{\mathrm{w}} \mathbf{u}=$}

The final piece of the puzzle involves the first person form $k^{w} u=$ which marks singular and plural objects as well as plural and some singular intransitive subjects. Newman (1979a) claims that this form is a borrowing from Kutenai $k u=$, analyzable as $k$-'subject marker' $+h u=$ 'first person.' The status of $k$ - is refined by Morgan (1991), which is certainly the most comprehensive investigation of Kutenai to date. Morgan shows that $h u=$ marks first person subjects regardless of number. The morpheme $k=$ is a subordinating proclitic which coalesces with the initial laryngeal consonant to yield $k u=$.

The fact that a pronoun is borrowed is startling enough, but the extent of restructuring of the pronominals it caused is equally striking. Thomason and Kaufman 1988 explain that this type of structural borrowing most likely points to intense contact. It does seem reasonable to view $k^{w} u=$ as a borrowing into Okanagan because its distribution does not match the rest of the pronominals. It is the only pronominal that is truly absolutive in its distribution, that is, it marks subjects of intransitive and objects of transitive clauses. In addition, as an object marker, its form and position differs from the rest of the paradigm: it is a proclitic, not a suffix. Most likely $k^{w} u=$ entered the Okanagan grammar as a marker of intransitive subject and then spread to other paradigms. The examples in (11) show that $k^{w} u=$ fits in nicely with the rest of the intransitive paradigm. 


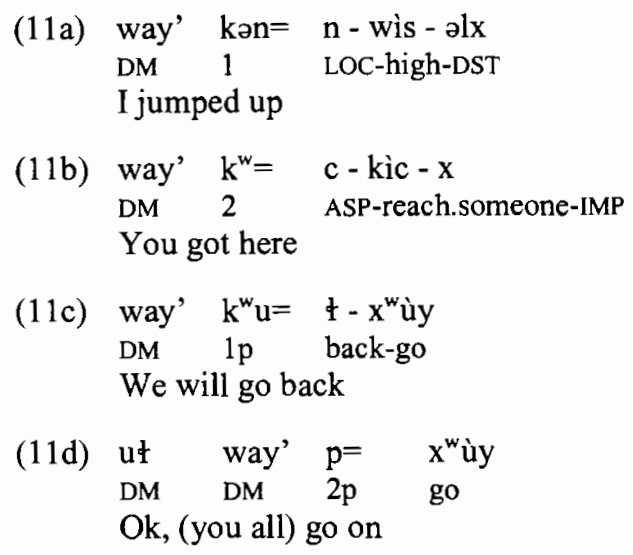

The examples in (11) show $k^{w} u=$ occurs in the same slot as the rest of the markers and it bears some phonological similarity with the first and second singular forms which are also velar-initial. Apart from the fact that these clauses are not subordinate, the use of $k^{w} u=$ in Okanagan matches its usage in Kutenai as proclitic marking first person.

Apparently $k^{w} u=$ did not replace the older singular form, $k \partial n=$, but N. Mattina (1996:172) reports that $k^{k} u=$ is used for first person singular in predicate nominal constructions involving kin or affinal terms. Compare (12a) and (12b) with (12c).

(12a) $\mathrm{k}^{\mathrm{w}} \mathrm{u}=\mathrm{P}^{\mathrm{P} i ́ w}-\mathrm{s}$

1 father-3Poss

I am his father

(12b) $\mathrm{k}^{\mathrm{w}} \mathrm{u}=\mathrm{kt}-\mathrm{ylmí} \mathrm{x}^{\mathrm{w}} ә \mathrm{~m}$

1 IRR-chief

I will be a chief

(nm1996:180)

(12c) kən= kł - na?ník'mn

$1 \quad$ IRR - knife

I will be a knife

(nm1996:175)

These data are based on her fieldwork and are presented in her dissertation. The data seem to illustrate an apparent split in the first person singular subject marking, shown in (12). The predicate in (12c) is not a kin or affinal term and therefore is marked with the older subject form $k \partial n=$. As a result, $k^{w} u=$ can be used to mark both singular and plural first person subjects, but its use with singular referents is limited. The fact that Okanagan preserves the older form $k \not n=$ is probably attributable to frequency.

Once this pronoun was borrowed, it would, of course, be used for the other function of the intransitive set: namely, marking objects of nominalizations, as was shown in examples (5) and (6). In the following examples, we find that when 
$k^{w} u=$ is used to mark an object, the form does not specify number. This ambiguity with respect to number matches its use in Kutenai.

(13a) uł $k^{w} a$ x̌əl stìm' $k i^{?} k^{w} u=a c-$ ən $-q^{\prime} a^{p}-$ ils - am $-s t-x^{w}(g w 369)$

DM DM for what that 1 ASP-LOC-business-feelings-INTR-LTR-2ERG

Why is it your business

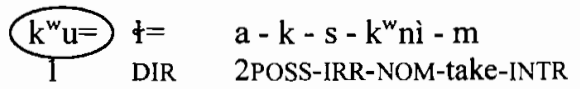

to take me

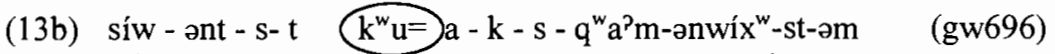
ask-HTR-2OBJ-1 pERG 1 2POSS-IRR-NOM-accustomed-RCP-LTR-INTR We ask you to give us an introduction

(13c) lut

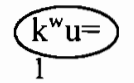

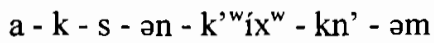

2POSS-IRR-NOM-LOC-unravel-back-INTR

Don't take the saddle off me

(13d) lut

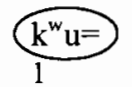

t'a $=$

k-s-c-ən-kcn-íkən'-(n)t-əm

IRR-NOM-LOC-overtake-back-HTR-INTR

She will never overtake us

In the examples above, the clauses in (13a) and (13b) show that $k^{w} u=$ marks first person objects of nominalizations regardless of their number. Similarly, (13c) and (13d) show that the strategy is also employed in negative constructions.

The important difference from the rest of the intransitive paradigm is that $k^{w} u=$ has permeated the transitive paradigm. That is, in addition to marking objects of nominalizations, it has also become the standard way mark all first person objects.

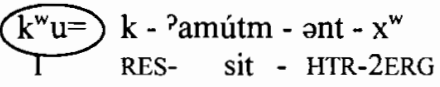

(You) stay with us

(14b)

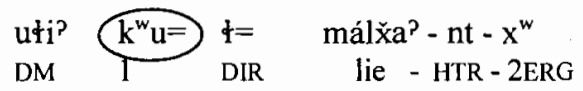

(gw305)

And then you lied to me

The examples above show that $k^{w} u=$ is used to mark first person objects in main clauses regardless of whether the referent is singular or plural. The fact that $k^{\mathrm{w}} u=$ is the only form from the intransitive set that marks objects in main clauses strengthens the hypothesis that $k^{w} u=$ is borrowed.

One question remains: how did $k^{w} u=$ actually come to mark objects in main clauses as well as nominalizations? The answer may lie in clauses with a third person agent acting on a first person plural patient. 
(15a)

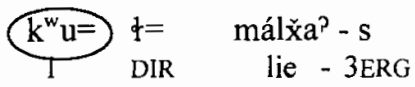

He lied to me

(15b) ut

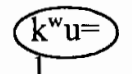

síw - ənt - əm

ask - HTR - INTR

DM

t. we were asked) $(\mathrm{gw} 302)$

(gw911)

The examples in (15) show that in clauses with third person agents and first person patients a distinction has been grammaticized in that clauses with first plural patients are detransitivized. The predicate resembles the indefinite forms seen in example (11). By detransitivizing, speakers are left with an intransitive clause, as in (15b), which will take the intransitive proclitic $k^{w} u=$. The ambiguity of number may have led to the spreading of $k^{\mu} u=$ to mark all first person objects, as in (15a). Eventually $k^{w} u=$ spread to mark first person objects with second person subjects, as in (15), but the motivation to detransitivize did not exist.

\section{Conclusion}

In the end, what initially appear to be anomalous forms in an already complex grammar turn out to be well-motivated internal restructuring of the language. Rather than being an arbitrary pattern of person marking, the formal similarities of the morphemes represent a realignment according to functional pressures in the diachronic development of the grammar of Okanagan. Detransitivization followed by reanalysis, as well as borrowing, helps to explain the allomorphy found in the person markers of Okanagan.

\section{References}

Chafe, Wallace. 1987. Cognitive constraints on information flow. In Russell S. Tomlin (ed.) Coherence and grounding in discourse, 21-51. Amsterdam: John Benjamins.

Comrie, Bernard and Sandra A. Thompson. 1985. Lexical Nominalization. In Timothy Shopen (ed.) Language typology and syntactic description, 349-398. Cambridge: Cambridge University Press.

Frachtenberg, Leo J. 1922. Siuslawan (Lower Umpqua). In Franz Boas (ed.) Handbook of American Indian Languages, vol. 2, 431-629. Washington DC: Bureau of Ethnology

Hebert, Yvonne. 1982a. Transitivity in Nicola Lake Okanagan. PhD dissertation, University of British Columbia.

Hebert, Yvonne. 1982b. Aspect and transitivity in (Nicola Lake) Okanagan. In Paul Hopper and Sandra A. Thompson (eds.) Syntax and Semantics 15:195215. New York: Academic Press.

Hopper, Paul and Sandra A. Thompson. 1980. Transitivity in grammar and discourse. Language 56:251-299. 
Kroeber, Paul. 1996. In the papers for the Thirtieth-first International Conference for Salish and Neighboring Languages, 197-202. Vancouver: UBC.

Kroeber, Paul D. 1999. The Salish language family: reconstructing syntax. Lincoln and London: University of Nebraska Press.

Mattina, Anthony. 1973. Colville Grammatical Structure. University of Hawaii Working Papers in Linguistics 5. Honolulu: University of Hawaii.

Mattina, Anthony. 1978a. The Colville Transitive System. In the papers for the Thirteenth International Conference for Salishan Languages. University of Victoria.

Mattina, Anthony. 1978b. Parallels between the Colville Transitives and PseudoIntransitives. In D. Malsch, J. Hoard and C. Sloat (eds.) Proceedings of the Eighth Annual Meeting of the Western Conference on Linguistics, Linguistics Research Inc., Edmonton, Alberta.

Mattina, Anthony. 1982. Colville-Okanagan transitive system. International Journal of American Linguistics, 48:421-435.

Mattina, Anthony. 1985. The Golden Woman: the Colville narrative of Peter J. Seymour. Tucson: University of Arizona Press.

Mattina, Anthony. 1987. Colville-Okanagan Dictionary. University of Montana Occasional Papers in Linguistics 5. Missoula: University of Montana.

Mattina, Anthony. 2001. In the papers for the Thirtieth-first International Conference for Salish and Neighboring Languages, 215-235. University of British Columbia Working Papers in Linguistics, 6. Vancouver: UBC

Mattina, Anthony and Timothy Montler. 1990. Towards a Reconstruction of the Proto-Salish Transitive System. Paper presented at the Third Spring Workshop on Theory and Method in Linguistic Reconstruction. Pittsburgh.

Mattina, Nancy. 1996. Aspect and Category in Okanagan Word Formation. PhD dissertation, Simon Fraser University.

Morgan, Lawrence R. 1991. A description of the Kutenai Language. PhD dissertation, University of California, Berkeley.

Newman, Stanley. 1979a. A history of Salish possessive and subject forms. International Journal of American Linguistics, 45:207-223.

Newman, Stanley. 1979b. The Salish object forms. International Journal of American Linguistics, 46:155-167.

Thomason and Kaufman 1988. Language Contact, Creolization and Genetic Linguistics. Berkeley:University of California Press.

Thompson, Laurence. 1985. Control in Salish grammar. In Frans Plank (ed.) Relational Typology, 391-428. Berlin: Mouton de Gruyter.

Paul Barthmaier

Department of Linguistics

University of California, Santa Barbara

Santa Barbara, CA 93106

ptb0@umail.ucsb.edu 